DOI 10.22460/jpmi.v1i3.401-408

\title{
PENGARUH METODE INKUIRI TERBIMBING TERHADAP KEMAMPUAN PENALARAN DAN SELF CONFIDENCE SISWA SMP
}

\author{
Neti Nuryanti $^{1}$, Tina Rosyana ${ }^{2}$, Euis Eti Rohaeti ${ }^{3}$ \\ 1,2,3 IKIP Siliwangi, Jl. Terusan Jenderal Sudirman, Cimahi, Jawa Barat, Indonesia \\ ${ }^{1}$ netinuryanti12@gmail.com, ${ }^{2}$ tinarosyana@gmail.com, ${ }^{3}$ e2rht@yahoo.com
}

Diterima: 20 April 2018; Disetujui: 28 Mei 2018

\begin{abstract}
This study aims to examine the achievement of mathematical reasoning ability and self-confidence of MTs students using guided inquiry method compared with using ordinary learning. The method used in this study is a quasi-experimental method, with a pretest and postes experimental-control group design. The population in this study is all MTs students in West Bandung regency, while the sample of the research is as much as two classes are selected to be experimental class and control class. The experimental class gained learning by guided inquiry method and the control class gained regular learning. The instrument used is a matter of reasoning ability test and non-test self-confidence matter. Data of research result are tested and analyzed quantitatively by using statistical test ( $t$ test). The conclusions obtained are as follows: 1 ) students' mathematical reasoning ability that obtains learning with guided inquiry method is better than students who gain ordinary learning; 2) the ability of selfconfidence students who gain learning with guided inquiry method is better than students who get regular learning.
\end{abstract}

Keywords: Mathematical Reasoning, Self Confidence, Guided Inquiry Method

\begin{abstract}
Abstrak
Penelitian ini bertujuan untuk menelaah pencapaian kemampuan penalaran matematis dan self confidence siswa MTs menggunakan metode inkuiri terbimbing dibandingkan dengan yang menggunakan pembelajaran biasa. Metode yang digunakan dalam penelitian ini adalah metode kuasi eksperimen, dengan desain kelompok eksperimen-kontrol pretes dan postes. Populasi pada penelitian ini adalah seluruh siswa MTs di Kabupaten Bandung Barat, sedangkan sampel penelitiannya adalah sebanyak dua kelas tersebut dipilih menjadi kelas eksperimen dan kelas kontrol. Kelas eksperimen memperoleh pembelajaran dengan metode inkuiri terbimbing dan kelas kontrol memperoleh pembelajaran biasa. Instrumen yang digunakan berupa soal tes kemampuan penalaran dan soal non tes self confidence. Data hasil penelitian diuji dan dianalisis secara kuantitatif dengan menggunakan uji statistik (uji t). Kesimpulan yang diperoleh adalah sebagai berikut: 1) kemampuan penalaran matematis siswa yang memperoleh pembelajaran dengan metode inkuiri terbimbing lebih baik daripada siswa yang memperoleh pembelajaran biasa; 2) kemampuan self confidence siswa yang memperoleh pembelajaran dengan metode inkuiri terbimbing lebih baik daripada siswa yang memperoleh pembelajaran biasa.
\end{abstract}

Kata Kunci: Penalaran Matematis, Self Confidence, Metode Inkuiri Terbimbing

How to cite: Nuryanti, N., Rosyana, T., \& Rohaeti, E. E. (2018). Pengaruh Metode Inkuiri Terbimbing terhadap Kemampuan Penalaran dan Self Confidence Siswa SMP. JPMI - Jurnal Pembelajaran Matematika Inovatif, 1 (3), 401-408. 


\section{PENDAHULUAN}

Matematika merupakan disiplin ilmu universal yang mendasari perkembangan teknologi modern dan berbagai disiplin ilmu serta mampu mengembangakan daya pikir manusia. Oleh karena itu, matematika perlu diajarkan di setiap jenjang pendidikan sebagai bekal pengembangan kemampuan menggunakan bahasa matematika dalam mengkomunikasikan ide atau gagasan matematika untuk memperjelas suatu situasi (Afrilianto, 2015)

Matematika merupakan salah satu ilmu pengetahuan yang memegang peranan penting dalam kehidupan manusia. Matematika sebagai ilmu pengetahuan yang diperoleh dari bernalar adalah suatu ilmu dasar dan salah satu disiplin ilmu yang sangat besar pengaruhnya terhadap kemajuan dan perkembangan ilmu pengetahuan (Rosyana \& Sari, 2015).

Matematika penting diterapkan di semua jenjang pendidikan. Tujuan pendidikan matematika menurut kurikulum 2013 (Kemendikbud, 2013) menekankan pada dimensi pedagogik modern dalam pembelajaran, yaitu menggunakan pendekatan Scientific (ilmiah). Dalam pembelajaran matematika kegiatan yang dilakukan agar pembelajaran bermakna yaitu mengamati, menanya, mencoba, menalar, menyaji, dan mencipta.

Kemampuan penalaran matematis merupakan salah satu aspek dalam tujuan pembelajaran matematika menurut rekomendasi Pedoman Teknis Peraturan Dirjen Dikdasmen Depdiknas Nomor 506/C/Kep/PP/2004 Romandhina (Hendriana, Rohaeti, Sumarmo, 2017). Indikator kemampuan penalaran matematis meliputi: 1) Mengajukan dugaan, 2) Melakukan manipulasi ide, 3) Menarik kesimpulan, menyusun bukti, memberikan alasan atau bukti terhadap kebenaran solusi, 4) Menarik kesimpulan dari pernyataan, 5) Memeriksa kesahihan suatu argumen, dan 6) Menemukan pola atau sifat dari gejala matematis untuk membuat generalisasi.

Penalaran matematis merupakan satu kemampuan matematis yang perlu dan penting dimiliki siswa Sekolah Menengah. Pentingnya pemilikan kemampuan penalaran matematik siswa pada dasarnya sejalan dengan visi matematika khususnya untuk memenuhi kebutuhan masa yang akan datang. Menurut Sumarmo (Hendriana, Rohaeti, Sumarmo, 2017) pembelajaran matematika diarahkan untuk memberi peluang berkembangnya kemampuan bernalar, kesadaran kebermanfaatan matematika, menumbuhkan rasa percaya diri, sikap objektif dan terbuka untuk menghadapi masa yang terus berubah. Keraf (Hendriana, Rohaeti, Sumarmo, 2017) menjelaskan bahwa istilah penalaran secara umum adalah "Proses berpikir yang berusaha menghubung-hubungkan fakta-fakta yang diketahui menuju kepada suatu kesimpulan".

Menurut Wahyudin (Hadi, 2016), kemampuan menggunakan penalaran sangat penting untuk memahami matematika dan menjadi bagian yang tetap dari pengalaman matematis para siswa. Bernalar secara matematis merupakan kebiasaan pikiran dan seperti semua kebiasaan lainnya.Namun kenyataannya, tujuan yang diharapkan tersebut belum tercapai seutuhnya. Hal ini dikarenakan berbagai masalah yang sering menjadi perbincangan yaitu rendahnya mutu pendidikan dan rendahnya prestasi belajar yang dicapai oleh siswa (Hermawan \& Hidayat, 2018; Hidayat, 2017; Hidayat \& Prabawanto; 2018).

Untuk meningkatkan hasil belajar siswa, guru dapat menerapkan model-model pembelajaran yang dapat meningkatkan aktivitas semangat belajar khususnya dalam belajar matematika, sehingga siswa menjadi antusias dan termotivasi dalam pelajaran khususnya matematika agar mendapatkan hasil belajar yang lebih baik (Nuraeni dan Rosyana, 2017) 
Berdasarkan pemaparan tersebut, kemampuan penalaran matematis penting dimiliki oleh semua siswa. Namun hasil PISA tahun 2015 menunjukkan bahwa kemampuan matematika dan sains siswa berada di urutan terbawah dengan skor matematika 386, menempatkan Indonesia pada peringkat ke 62 dari 70 negara. Jika bernalar dengan menggunakan tabel/grafik hanya $4 \%$ benar. Adapun studi ini menilai kemampuan siswa untuk menganalisis dan bernalar, yang melibatkan konsep-konsep matematika.

Salah satu sikap yang mendukung kemampuan penalaran matematis adalah kepercayaan diri (Self Confidence). Hal tersebut dijelaskan oleh Yates (Hendriana, Rohaeti, Sumarmo, 2017) bahwa kepercayaan diri sangat penting bagi siswa agar berhasil dalam belajar matematika. Kepercayaan diri juga akan memberikan motivasi terhadap pencapaian keberhasilan seseorang dalam memecahkan permasalahan yang dihadapi. Sehingga semakin tinggi kepercayaan diri seseorang terhadap kemampuan diri sendiri, semakin kuat pula semangat untuk menyelesaikan pekerjaannya (Hendriana, 2014; Sholihat, Hidayat, \& Rohaeti, 2018; Sumarmo, Mulyani, \& Hidayat, 2018; Tresnawati, Hidayat, \& Rohaeti, 2017).

Selain kemampuan penalaran dan self confidence siswa perlu di dukung dengan pembelajaran aktif dan lebih bermakna. Salah satu pembelajaran inovatif adalah pembelajaran menggunakan metode inkuiri terbimbing. Metode ini memberikan kesempatan kepada siswa agar mereka aktif mencari dan menemukan konsep serta kesimpulan sendiri mengenai konsep tersebut tapi tentunya selalu dalam pengawasan, pengarahan dan bimbingan guru. Siswa diberikan kesempatan melatih kemampuannya dengan merumuskan masalah, mengajukan hipotesis, mengumpulkan data, dan memberikan kesimpulan sehingga mereka dilatih dalam menganalisa dan memberikan alasan-alasan untuk mengukur penalaran matematis siswa (Hendriana, Rohaeti, \& Hidayat, 2017).

Penelitian ini merupakan hasil observasi. Tujuan penelitian ini untuk menelaah kemampuan penalaran matematis dan self confidence siswa kelas VIII MTs di Kabupaten Bandung Barat pada materi bangun ruang sisi datar. Ketika kemampuan penalaran siswa telah diketahui, selanjutnya guru harus merancang pembelajaran yang membiasakan siswa untuk melakukan penalaran matematis, sehingga kemampuan siswa dapat meningkat.

\section{METODE}

Metode penelitian yang digunakan adalah penelitian kuasi eksperimen (pemilihan sampel berdasarkan kelas) yang melibatkan dua kelompok yaitu kelompok eksperimen yang mendapat pembelajaran dengan metode inkuiri terbimbing dan kelompok kontrol yang mendapat pembelajaran dengan metode biasa. Pada awal dan akhir pembelajaran kedua kelas diberi tes sehingga desain penelitiannya (Ruseffendi, 2010) sebagai berikut:

\section{O $\mathbf{X} \mathbf{O}$}

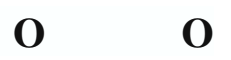

Keterangan:

O : Tes awal dan tes akhir kemampuan penalaran

$\mathrm{X} \quad$ : Pembelajaran dengan menggunakan metode inkuiri terbimbing

----- : Pengambilan sampel tidak acak 
Populasi pada penelitian ini adalah seluruh siswa di salah satu MTs di Kabupaten Bandung Barat semester genap Tahun Pelajaran 2017-2018. Sampel yang diambil dalam penelitian ini adalah dua kelas siswa kelas VIII sebagai kelas eksperimen dan kelas kontrol. Instrumen yang digunakan adalah instrumen tes berbentuk soal uraian untuk mengukur kemampuan penalaran siswa.

\section{HASIL DAN PEMBAHASAN}

\section{Hasil}

\section{Analisis Hasil Penelitian Menggunakan Uji Statistik}

Pada bagian ini disajikan data hasil penelitian serta analisis menggunakan uji statistik. Data deskriptif hasil penelitian sebelum dan sesudah pembelajaran disajikan dalam tabel 1 berikut:

Tabel 1. Rekapitulasi Hasil Pretes Postes Kemampuan penalaran matematis

\begin{tabular}{lccc}
\hline \multicolumn{1}{c}{ Kelas } & Tes & statistik & Penalaran matematis \\
\hline Eksperimen & Pretes & $\overline{\mathrm{X}}$ & 4,04 \\
& & $\mathrm{~S}$ & 1,40 \\
& Postes & $\overline{\mathrm{X}}$ & 16,87 \\
\multirow{3}{*}{ Kontrol } & & $\mathrm{S}$ & 2,91 \\
& Pretes & $\overline{\mathrm{X}}$ & 3,96 \\
& & $\mathrm{~S}$ & 11,22 \\
& \multirow{2}{*}{ Postes } & $\overline{\mathrm{X}}$ & 1,52 \\
& & $\mathrm{~S}$ & 2,41 \\
\hline
\end{tabular}

\section{Analisis Data Pretes Kemampuan Penalaran Matematik}

Analisis data pretes dilakukan dengan perhitungan uji perbedaan rataan data pretes kemampuan penalaran siswa kelas eksperimen dan kelas kontrol menggunakan uji non parametik Mann Whitney. Hasilnya disajikan pada tabel 2.

Tabel 2. Hasil Uji Perbedaan Rataan Pretes Kemampuan Penalaran Matematik

\begin{tabular}{lccc}
\hline \multirow{2}{*}{$\begin{array}{l}\text { Aspek Kemampuan } \\
\text { Penalaran Matematik }\end{array}$} & \begin{tabular}{c} 
Mann Whitney- \\
\cline { 2 - 4 }
\end{tabular} & $\begin{array}{c}\text { Asymp. Sig (2- } \\
\text { tailed) }\end{array}$ & $\mathrm{H}_{0}$ \\
\cline { 2 - 4 } & 256,500 & 0,857 & Ditolak \\
\hline
\end{tabular}

Hipotesis yang diuji untuk kemampuan awal matematik yaitu:

$\mathrm{H}_{0}$ : Kemampuan penalaran matematis siswa kelas eksperimen tidak lebih baik dari atau sama dengan kelas kontrol

$\mathrm{H}_{1}$ : Kemampuan penalaran matematis siswa kelas eksperimen lebih baik daripada kelas kontrol 
Kriteria pengujian, jika nilai probabilitas (sig) lebih dari 0,05 , maka $\mathrm{H}_{0}$ diterima. Berdasarkan Tabel 2 diatas, hipotesis nol diterima, sehingga hipotesis kedua atau $\mathrm{H}_{1}$ ditolak. Dengan demikian dapat disimpulkan bahwa kemampuan penalaran matematis siswa kelas eksperimen tidak lebih baik dari kelas kontrol.

\section{Analisis Data Postes Kemampuan Penalaran Matematis}

Tabel 3. Hasil Uji Perbedaan Rataan Postes Kemampuan Penalaran Matematis

\begin{tabular}{lccc}
\hline \multirow{2}{*}{ Aspek kemampuan } & Mann Whitney- & Asymp. Sig (2-tailed) & $\mathrm{H}_{0}$ \\
\cline { 2 - 4 } Penalaran Matematik & $U$ & & \\
\cline { 2 - 4 } & 32,500 & 0,000 & Diterima \\
\hline
\end{tabular}

Hipotesis yang diuji untuk kemampuan awal matematis yaitu:

$\mathrm{H}_{0}$ : Kemampuan penalaran matematis siswa kelas eksperimen tidak lebih baik dari atau sama dengan kelas kontrol

$\mathrm{H}_{1}$ : Kemampuan penalaran matematis siswa kelas eksperimen lebih baik daripada kelas kontrol.

Kriteria pengujian, jika nilai probabilitas (sig) lebih dari 0,05 , maka $\mathrm{H}_{0}$ diterima, jika (sig) kurang dari $0,05 \mathrm{H}_{0}$ ditolak. Berdasarkan tabel 3 diatas, hipotesis nol ditolak, sehingga hipotesis kedua atau $\mathrm{H}_{1}$ diterima. Dengan demikian dapat disimpulkan bahwa kemampuan komunikasi matematik siswa kelas eksperimen lebih baik dari kelas kontrol.

\section{Analisis Data Pretes Self Confidence}

Tabel 4. Hasil Uji Perbedaan Rataan Pretest Self Confidence

\begin{tabular}{cccc}
\hline $\begin{array}{c}\text { Pernyataan Self } \\
\text { Confidence }\end{array}$ & $\begin{array}{c}\text { Mann Whitney- } \\
\boldsymbol{U}\end{array}$ & $\begin{array}{c}\text { Asymp. Sig }(2- \\
\text { tailed })\end{array}$ & $\mathbf{H}_{\mathbf{0}}$ \\
\hline 1 & 255,000 & 0,819 & Diterima \\
2 & 259,500 & 0,900 & Diterima \\
3 & 254,00 & 0,806 & Diterima \\
4 & 252,00 & 0,766 & Diterima \\
5 & 240,500 & 0,562 & Diterima \\
\hline
\end{tabular}

Hipotesis yang diuji untuk kemampuan awal adalah:

$\mathrm{H}_{0}$ : Self confidence siswa kelas eksperimen tidak lebih baik dari atau sama dengan kelas kontrol

$\mathrm{H}_{1}$ : Self confidence siswa kelas eksperimen lebih baik daripada kelas kontrol.

Kriteria pengujian ini jika nilai signifikasi lebih dari 0,05 , maka $\mathrm{H}_{0}$ diterima dan $\mathrm{H}_{1}$ ditolak. Dan jika nilai signifikasi kurang dari 0,05 maka $\mathrm{H}_{0}$ ditolak dan $\mathrm{H}_{1}$ diterima. Berdasarkan tabel 4 diatas maka Pernyataan 1 sampai dengan 5, nilai signifikansinya lebih dari 0,05 maka $\mathrm{H}_{0}$ diterima dan $\mathrm{H}_{1}$ ditolak, artinya kemampuan self confidence siswa kelas eksperimen tidak lebih baik atau sama dengan kelas kontrol. 


\section{Analisis Data Postes Self Confidence}

Tabel 5. Hasil Uji Perbedaan Rataan Pretes Self Confidence

\begin{tabular}{cccc}
\hline $\begin{array}{c}\text { Pernyataan } \\
\text { Self Confidence }\end{array}$ & $\begin{array}{c}\text { Mann Whitney- } \\
\text { U }\end{array}$ & $\begin{array}{c}\text { Asynp. Sig (2- } \\
\text { tailed) }\end{array}$ & $\mathbf{H}_{\mathbf{0}}$ \\
\hline 1 & 103.000 & 0,000 & ditolak \\
2 & 150,00 & 0,003 & ditolak \\
3 & 95,000 & 0,000 & ditolak \\
4 & 111,500 & 0.000 & ditolak \\
5 & 91,500 & 0,000 & ditolak \\
\hline
\end{tabular}

Hipotesis yang diuji untuk kemampuan self confidence adalah:

$\mathrm{H}_{0} \quad$ : Self confidence siswa kelas eksperimen tidak lebih baik dari atau sama dengan kelas kontrol

$\mathrm{H}_{1} \quad$ : Self confidence siswa kelas eksperimen lebih baik daripada kelas kontrol.

Kriteria pengujian ini jika nilai signifikasi lebih dari 0,05 , maka $\mathrm{H}_{0}$ diterima dan $\mathrm{H}_{1}$ ditolak. Dan jika nilai signifikasi kurang dari 0,05 maka $\mathrm{H}_{0}$ ditolak dan $\mathrm{H}_{1}$ diterima. Berdasarkan tabel 4 diatas maka Pernyataan 1 sampai dengan 5, nilai signifikasi kurang dari 0,05 maka $\mathrm{H}_{0}$ ditolak dan $\mathrm{H}_{1}$ diterima, artinya setelah mendapat pembelajaran dengan menggunakan metode inkuiri terbimbing, kemampuan self confidence siswa kelas eksperimen lebih baik daripada kelas kontrol.

\section{Pembahasan}

Pembahasan hasil penelitian ini didasarkan pada faktor-faktor yang dicermati dalam penelitian ini. Faktor-faktor tersebut adalah pembelajaran metode inkuiri terbimbing dan self confidence. Berdasarkan analisis data hasil penelitian diperoleh bahwa siswa yang mendapatkan pembelajaran menggunakan metode inkuiri terbimbing berpengaruh terhadap kemampuan penalaran matematis dan self confidence siswa.

Kelas yang mendapatkan pembelajaran dengan menggunakan metode inkuiri terbimbing telah berjalan sesuai dengan harapan. Berikut ini ulasan mengenai pelaksanaan penelitian yang dilakukan:

a. Sebelum memulai pembelajaran, peneliti membagi kelompok secara heterogen yang terdiri dari 4 orang siswa. Lalu peneliti membagikan LKS yang harus dikerjakan secara berkelompok.

b. Peneliti membacakan pertunjuk untuk mengisi LKS tersebut, dimana telah disajikan persoalan mengenai materi yang akan ditemukan. Anggota kelompok diharapkan dapat menhajukan hipotesis dari persoalan yang diberikan. Peneliti hanya membimbing jalannya pembelajaran.

c. Setelah selesai mengerjakan LKS tersebut, peneliti meminta salah satu perwakilan dari kelompok untuk menuliskan hasil diskusi bersama kelompoknya, kelompok lain memperhatikan dan dipersilahkan untuk memberi masukan atau menyanggah tentang apa yang didapatkan oleh kelompok lain sehingga terjadi diskusi. Dalam hal ini self confidence siswa akan terlihat dimana mengeluarkan ide-ide dan pendapat yang mereka miliki. 
d. Setelah diskusi selesai, peneliti dan siswa menyimpulkan materi bersama-sama. Kemudian melakukan refleksi dan evaluasi terhadap persoalan pada LKS dengan membimbing siswa memahami konsep matematika formal.

Untuk mengetahui hasil belajar siswa dari dua kelas yang menjadi sampel penelitian, maka diberikan pretes dan postes. Pretes diberikan sebelum pembelajaran, bertujuan untuk melihat kemampuan awal siswa tentang kemampuan komunikasi dan self confidence berkenaan dengan materi yang diberikan. Pada tes awal yang dilakukan (pretes) perbedaan kemampuan penalaran yang diperoleh kedua kelas relatif sama. Ini dapat dilihat pada tabel. 1 .

Setelah mendapatkan pembelajaran yang berbeda selama 8 kali pertemuan, maka diadakan postes di kelas eksperimen dan kelas kontrol. Postes diberikan bertujuan untuk mengetahui sejauh mana perkembangan kemampuan penalaran matematik dan self confidence siswa. hasil rata-rata postes yang didapat dapat dilihat pula di tabel 1 .

Untuk analisis kemampuan penalaran dari data hasil pretes dan postes dilakukan dikedua kelas, terdapat peningkatan kemampuan penalaran pada kelas eksperimen. Saat pretes menurut perhitungan menggunakan uji Man Whitney kemampuan penalaran matematik siswa kelas eksperimen tidak lebih baik dari atau sama dengan kelas kontrol.

Namun setelah kelas eksperimen memperoleh pembelajaran dengan metode inkuiri terbimbing, pada hasil postes terdapat perubahan yaitu kemampuan penalaran matematis siswa kelas eksperimen lebih baik dari pada kelas kontrol.

Begitu juga dengan kemampuan self confidence siswa, pada saat dilakukan pretes kelas eksperimen dan kelas kontrol tidak terlihat perbedaan yang signifikan, artinya kemampuan self confidence keduanya relatif sama. Tetapi ketika dilakukan postes, terjadi perbedaan yang signifikan dari kelas eksperimen dan kelas kontrol, hal ini dibuktikan dengan self confidence siswa di kelas eksperimen lebih baik dibandingkan siswa di kelas kontrol.

\section{KESIMPULAN}

Dari uraian pembahasan diatas dapat disimpulkan bahwa: (1) Kemampuan penalaran matematis siswa yang memperoleh pembelajaran dengan metode inkuiri terbimbing lebih baik daripada siswa yang memperoleh pembelajaran biasa; (2) Kemampuan self confidence siswa yang memperoleh pembelajaran dengan metode inkuiri terbimbing lebih baik daripada siswa yang memperoleh pembelajaran biasa.

\section{DAFTAR PUSTAKA}

Afrilianto, M. (2015). Pengaruh Pendekatan Model-Eliciting Activities Terhadap Kemampuan Komunikasi Matematik Siswa SMP. Ilmiah, 2(1), 40-45.

Hadi, W. (2016). Meningkatkan kemampuan penalaran siswa SMP melalui pembelajaran discovery dengan pendekatan saintifik (Studi kuasi eksperimen di salah satu SMP Jakarta Barat). Kalamatika, I(1), 93-108.

Hendriana, H., Rohaeti, E. E., \& Hidayat, W. (2017). Metaphorical Thinking Learning and Junior High School Teachers' Mathematical Questioning Ability. Journal on Mathematics Education, 8(1), 55-64. 
Hendriana, H., Rohaeti, E.T., Sumarmo, U. (2017). Hard Skills dan Soft Skills Matematik Siswa. (N. . Atif, Ed.). Bandung: Refika Aditama.

Hendriana, H. (2014). Membangun Kepercayaan Diri Siswa Melalui Pembelajaran Matematika Humanis. Jurnal Pengajaran MIPA, 19, Nomor, 52-60.

Hermawan, A. S., \& Hidayat, W. (2018). Meningkatkan Kemampuan Penalaran Matematik Siswa SMP Melalui Pendekatan Penemuan Terbimbing. JPMI (Jurnal Pembelajaran Matematika Inovatif), 1(1), 7-20.

Hidayat, W. (2017). Adversity Quotient dan Penalaran Kreatif Matematis Siswa SMA dalam Pembelajaran Argument Driven Inquiry pada Materi Turunan Fungsi. KALAMATIKA Jurnal Pendidikan Matematika, 2(1), 15-28.

Hidayat, W., \& Prabawanto, S. (2018, January). Improving students' creative mathematical reasoning ability students through adversity quotient and argument driven inquiry learning. In Journal of Physics: Conference Series (Vol. 948, No. 1, p. 012005). IOP Publishing.

Kemendikbud. (2013). Permendikbud No.64 tentang Standar Isi Pendidikan Dasar dan Menengah. Jakarta: Kementrian Pendidikan dan Kebudayaan.

Nuraeni, W dan Rosyana, T. (2017). Prosiding Seminar Nasional Matematika dan Pendidikan Matematika. Program Studi Pendidikan Matematika STKIP Siliwangi Bandung, p. 1654.

Rosyana, T., \& Sari, I. P. (2015). P2M STKIP Siliwangi MELALUI PENDEKATAN THINKING ALOUD PAIR PROBLEM SOLVING. UPT P2M STKIP Siliwangi, 2(2), 192-202.

Ruseffendi, E. T. (2010). Dasar-Dasar Penelitian Pendidikan \& Bidang Non-Eksakta Lainnya. Bandung: Tarsito.

Sholihat, N. A. N., Hidayat, W., \& Rohaeti, E. E. (2018). Faktor Kemampuan Penalaran Matematis dan Penghargaan Diri Siswa SMP. JPMI (Jurnal Pembelajaran Matematika Inovatif), 1(1), 1-6.

Sumarmo, U., Mulyani, E., \& Hidayat, W. (2018). Mathematical Communication Ability and Self Confidence Experiment with Eleventh Grade Students Using Scientific Approach. JIML-Journal of Innovative Mathematics Learning, 1(1), 19-30.

Tresnawati, T., Hidayat, W., \& Rohaeti, E. E. (2017). Kemampuan Berpikir Kritis Matematis dan Kepercayaan Diri Siswa SMA. Symmetry: Pasundan Journal of Research in Mathematics Learning and Education, 2(2), 39-45. 